\title{
Socio-demographic Characteristics and Diagnostic Profile of Patients Attending Psychiatric OPD of a Private Hospital in Western Region of Nepal
}

\author{
Khattri JB, ${ }^{1 *}$ Godar ST, ${ }^{2}$ Thapa , $^{1}$ Ramesh ${ }^{1},{ }^{1}$ Chakrabortty PK, ${ }^{1}$ Thapa BB ${ }^{3}$ \\ ${ }^{1}$ Department of Psychiatry, ${ }^{2}$ Department of Opthalmology, Manipal Teaching Hospital, Pokhara, Nepal \\ ${ }^{3}$ Department of Internal Medicine, Western Regional Hospital, Pokhara, Nepal
}

\section{* Corresponding Author: \\ Dr. Jai Bahadur Khattri, MBBS, MD Assistant Professor, Dept of Psychiatry \\ Manipal Teaching Hospital, Pokhara, Nepal \\ Email:jai_khattri@yahoo.com}

\section{Citation}

Khattri JB, Godar ST, Thapa P, Ramesh K, Chakrabortty $P K$, Thapa BB. Socio-demographic characteristics and diagnostic profile of patients attending psychiatric OPD of a private hospital in western region of Nepal. Nepal Journal of Medical Sciences. 2012; 1(1): 15-18.

\begin{abstract}
Background: Mental health services in Nepal are limited and there is a scarcity of epidemiological studies in our country. The present study is done with the aim to study the socio-demographic characteristic and diagnostic profile of patients attending the psychiatric OPD.
\end{abstract}

Methods: This is a retrospective study where case records of all new patients, diagnosed to be suffering from Mental and Behavioral disorders according to Chapter V (F) of ICD-10, who attended the OPD from July 2011 to December 2011, were included in the study.

Results: Maximum patients fall in the younger age group and are females. The patients were found to be suffering from neurotic, stress-related and somatoform disorders (35.4\%) followed by mood disorder (18.3\%), schizophrenia, schizotypal and delusional disorders (17.4\%) and mental and behavioral disorders due to psychoactive substance use (9.7\%).

Conclusion: Mental disorders comprise a wide variety of disorders and affect the most productive age group suggesting the need for early identification and prompt management.

Keywords: ICD-10 DCR; psychiatric OPD; psychiatric morbidity; neurotic disorders

\section{Background:}

S Studies regarding psychiatric morbidity are scarce in Nepal. The pattern of psychiatric illnesses has been described to be similar across the countries. In spite of that the culture plays an important role on the morbidity pattern in a community is also an acknowledge fact. ${ }^{1,2}$ The studies in this aspect becomes important, mainly to formulate any plan regarding mental illness. There are few studies on mental illness in Nepal, but the diagnostic profile differed among the studies. ${ }^{3-9}$ Psychiatric service and mental health are behind the scene in national health policy and priority in Nepal. ${ }^{10-11}$

Western governments are increasingly looking to the public-private partnerships (PPP) model to solve larger problems in healthcare delivery. There is not a single country in the world where healthcare is financed entirely by the government. While the provision of health is widely recognized as the responsibility of government, private capital and expertise are increasingly viewed as welcome sources to induce efficiency and innovation. As PPPs move from financing infrastructure to managed care delivery, there is an opportunity to reduce overall cost of healthcare.

Majority of the studies in Nepal have focused in capital city and there is a paucity of information about psychiatric morbidity pattern from private sector in western region of Nepal. The present work was undertaken with the aim to study the socio-demographic characteristics and diagnostic profile of patients attending the psychiatry OPD of a private hospital situated in Pokhara valley. 
Pokhara Sub-Metropolitan City is the second largest city of Nepal and is the headquarters of Kaski District, Gandaki Zone and capital of geographical Central Nepal i.e., Western Development Region. The catchment areas of the hospital were mainly from the Kaski District having population of 490,429 because of its geographical location. ${ }^{12}$ However, the patients are frequently referred from other hospitals or they come of their own from the other part of western region of Nepal in order to get the tertiary care treatment in this hospital. Very often the patients have to travel long distances over a few days to reach here.

\section{Methods:}

New patients attending Psychiatry OPD of Fewa City Hospital and Research Centre over a period of six months (from July 2011 to December 2011) were included in the study. The consent was taken from the patients or patients relative. Consent was taken from the relatives of the patients if there was suspicion of cognitive decline or if the patient is unable to give adequate information. A self-designed proforma was used to record the sociodemographic data and detail history and mental state examination was done. Then, retrospective analyses of case records were done. All new cases are diagnosed according to $\mathrm{F}$ category of International Classification of Diseases, $10^{\text {th }}$ revision (ICD-10) [WHO, 1992]. ${ }^{13}$ Data analysis was done in epi-info 6 version.

\section{Results:}

Table 1 shows the distribution of the respondent as per age and sex. Majority of the patients falls in the age groups between 21-30 (25.7\%) and 31-40 (24.1\%). Females $(50.4 \%)$ are slightly more than males $(49.6 \%)$.

Table 1: Age and sex-wise distribution of the patients

\begin{tabular}{ccccc}
\hline $\begin{array}{c}\text { Age-groups } \\
\text { (in years) }\end{array}$ & Male & Female & N & \% \\
\hline $\mathbf{0 - 1 0}$ & 7 & 6 & 13 & 1.4 \\
$\mathbf{1 1 - 2 0}$ & 49 & 57 & 106 & 11.9 \\
$\mathbf{2 1 - 3 0}$ & 121 & 107 & 228 & 25.7 \\
$\mathbf{3 1 - 4 0}$ & 113 & 101 & 214 & 24.1 \\
$\mathbf{4 1 - 5 0}$ & 72 & 76 & 148 & 16.6 \\
$\mathbf{5 1 - 6 0}$ & 37 & 65 & 102 & 11.4 \\
$>\mathbf{6 0}$ & 41 & 35 & 76 & 8.5 \\
TOTAL & 440 & 447 & 887 & 100 \\
Mean age & $36.68 \pm 15.66$ & $37.84 \pm 16.10$ & $37.26 \pm 15.89$ \\
\hline
\end{tabular}

Table 2 shows the distribution of respondents on the basis of ICD-10 Diagnostic Criteria for Research diagnosis. Majority of the cases were suffering from neurotic, stress-related and somatoform disorders $(35.4 \%)$. This is followed by mood disorder (18.3\%), schizophrenia, schizotypal and delusional disorders (17.4\%) and mental and behavioral disorders due to psychoactive substance use $(9.7 \%)$.

\section{Table 2: Diagnosis according to ICD-10 Criteria}

\begin{tabular}{|c|c|c|c|c|c|}
\hline ICD-10 category & $\begin{array}{l}\text { ICD-10 } \\
\text { code }\end{array}$ & Male & Female & TOTAL & $\%$ \\
\hline $\begin{array}{l}\text { Organic, including } \\
\text { symptomatic, mental disorders }\end{array}$ & F00-F09 & 13 & 10 & 23 & 2.6 \\
\hline $\begin{array}{l}\text { Mental and behavioral } \\
\text { disorders due to psychoactive } \\
\text { substance use }\end{array}$ & F10-F19 & 83 & 3 & 86 & 9.7 \\
\hline $\begin{array}{l}\text { Schizophrenia, Schizotypal and } \\
\text { Delusional disorders }\end{array}$ & F20-F29 & 84 & 70 & 154 & 17.4 \\
\hline Mood disorders & F30-F39 & 71 & 91 & 162 & 18.3 \\
\hline $\begin{array}{l}\text { Neurotic, stress-related and } \\
\text { somatoform disorders }\end{array}$ & F40-F48 & 119 & 195 & 314 & 35.4 \\
\hline $\begin{array}{l}\text { Behavioural syndromes } \\
\text { associated with physiological } \\
\text { disturbances and physical } \\
\text { factors }\end{array}$ & F50-F59 & 4 & 0 & 4 & 0.5 \\
\hline Mental retardation & F70-F79 & 2 & 0 & 4 & 0.2 \\
\hline $\begin{array}{l}\text { Behavioural and emotional } \\
\text { disorders with onset usually } \\
\text { occurring in childhood and } \\
\text { adolescence }\end{array}$ & F90-F98 & 2 & 0 & 4 & 0.2 \\
\hline Headache & G43\&44 & 16 & 39 & 55 & 6.2 \\
\hline Seizure disorder & G40\&41 & 45 & 38 & 83 & 9.4 \\
\hline Movement Disorders & $\mathrm{G} 25$ & 1 & 1 & 2 & 0.2 \\
\hline TOTAL & & 440 & 447 & 887 & 100 \\
\hline
\end{tabular}

\section{Discussion:}

A high prevalence of morbidity is seen in the younger age group in the current sample (Table 1). This is in concordance with the study done in other setting in Nepal ${ }^{7,9}$ and in India. ${ }^{14,15}$ Soren et al commented that this may be due to inclusion of epilepsy and mental retardation, both being disorders having early age of onset. ${ }^{14}$ The awareness or concern of this age group for mental and behavioral disorders might also have contributed to this observation. ${ }^{14}$

Approximately $65 \%$ of the population were less than 40 years of age and is followed by gradual decline as age progresses (Table 1). Similar tendency were also reported by earlier workers. ${ }^{7,9,16-18}$

Present study shows psychiatric morbidity more in females (50.4\%) than in males (49.6\%) (Table 2). Dubey in his field survey in Uttar Pradesh, India found a high prevalence of mental morbidity in females than in males. ${ }^{16}$ Nandi et al 
also corroborated this finding in their study in Bengal. ${ }^{19}$ Two studies in Nepal in 1999 found high prevalence in males than in females. ${ }^{7,9}$ According to National Population and Housing Census 2012, absentee population in Nepal increased to $1,917,903$ which are more than double the absentee population in 2001. Apparently, the population of male absentees dominates and comprises $87 \%$ of total absentees. Kaski district has total of 57,238 absentee population out of which $47,853(83.6 \%)$ are males. Sex ratio is estimated to be 94.4 (male per hundred female) in the current census. ${ }^{12}$ This may also be explained by change in the societal perception about gender. However, these issues need to be further researched.

This study showed that most of the service seekers were those who were suffering from neurotic, stress-related and somatoform disorders $(35.4 \%)$, followed by the patients suffering from mood disorders (18.3\%), schizophrenia, schizotypal and delusional disorders (17.4\%) and mental and behavioral disorders due to use of psychoactive substance $(9.7 \%)$ (Table 2). Although our findings are similar to the findings reported by Nepal et al $(1986)^{3}$ and Regmi et al (1999), ${ }^{7}$ these findings are much different from other earlier studies. The largest diagnostic group in Nepal et al in the first 150 patients attending the Psychiatry OPD of Tribhuvan University Teaching Hospital (TUTH), Kathmandu was neurotic and related disorders followed by depression and schizophrenia. ${ }^{3}$ Regmi et al also conducted study at TUTH found neurotic, stress-related and somatoform disorders (42.4\%) as the main psychopathology followed by mood disorders (37.2\%) and schizophrenia, schizotypal \& delusional disorders $(8.7 \%){ }^{7}$

Wright (1987) had found that $32 \%$ of the patients were suffering from epilepsy, $25 \%$ from psychosis and 13\% from depression. ${ }^{8}$ Sharma (1987) described $42 \%$ of the patients in his study to be suffering from depression, $17 \%$ from neurosis and 16\% from epilepsy. ${ }^{5}$ In the study by Shrestha (1987), 63.7\% of the patients were suffering from psychosis, $18 \%$ from neurosis and $6 \%$ from epilepsy. ${ }^{4}$

Study conducted in the same city as this study in the year 2009 at western regional hospital (government run hospital) in Pokhara, mood disorders emerged as the largest group (29\%), followed by neurotic, stress-related and somatoform disorders (24.2\%), schizophrenia, schizotypal and delusional disorders (10.5\%) and mental and behavioral disorders due to psychoactive substance use $(7.3 \%) .{ }^{9}$ Soren et al in a study conducted in Jharkhand, India found affective psychosis $(31.9 \%)$ as the main psychiatric problem followed by non-affective psychosis (18.8\%), epilepsy (15.8\%) and neurotic disorder (11.2\%). ${ }^{14}$ Waraich et al had found $6.8 \%$ nonaffective psychosis, $40.3 \%$ females were suffering from mood disorders and $29.7 \%$ from anxiety disorders, $2.4 \%$ were suffering from epilepsy. ${ }^{20}$ The Raipur Rani study in India reported schizophrenia in 11\%, Manic-depressive psychosis in $18 \%$, epilepsy in $13.8 \%$, anxiety neurosis in $22 \%$, depressive neurosis in $21 \%$. $^{21}$

Our findings are also similar to the findings of the study by Dubey (1970), which was conducted in the rural community of Uttar Pradesh (India), in which about $44 \%$ of the patients were suffering from neurotic and related disorders and 9.1\% from schizophrenia. ${ }^{16}$ However, the studies conducted in the out-patients in other parts of the world are rather similar to the findings of Shrestha (1987), ${ }^{4}$ in which most of the patients were suffering from psychotic disorders, and less were suffering from neurotic disorders. ${ }^{22,23}$

It is also likely that with increasing awareness more patients with neurotic and other minor mental disorders will report for treatment. The anxiety symptoms are associated with significant distress including concern about implication and consequences and are, therefore, more likely to come for treatment. Long standing somatic symptoms of neurotic disorders also makes the patient to visit multiple hospitals to relieve their distress immediately.

Personality disorders are ego-syntonic; hence patients are least likely to avail treatment. Also, personality disorders are generally considered as an axis II diagnosis. In this study, primary diagnosis was given much more importance.

Epilepsy was seen in $9.4 \%$ of the population in the current sample (Table 2). This is lower $(18.2 \%)$ than the study conducted by Upadhaya et al. ${ }^{9}$ This may be due to availability of neurosurgical services in our nursing home which was not available at western regional hospital in 1999. Mental and behavioral disorders due to psychoactive substance use comprised $9.7 \%$ of the sample which is almost similar $(10.5 \%)$ to the study conducted in the same area. ${ }^{9}$

The reasons of the difference may be many which includes the cultural factors, literacy rate in the different areas where the studies are conducted, and the setup e.g. psychiatry OPD of general hospital, mental hospital, private clinic, and health posts, but the most important factor is that the studies had used older concepts of 'neurosis' and 'psychosis' which is now obsolete.

\section{Conclusion:}

Mental disorders comprise a wide variety of disorders; consist mainly of neurotic and mood disorders which present with somatic symptoms. It affects the most productive age groups, affecting the economic status of the person and a country as a whole. Majority of the mental disorders have a good prognosis, suggesting the need for early identification 
and prompt management. Awareness program in public about somatic symptoms in mental disorders will definitely be of help.

\section{References:}

1. Leff JP. Culture and the differentiation of emotional states. Br J Psychiatry 1973;123: 299-306.

2. Neki JS. Psychiatry in South-Asia. Br J Psychiatry 1973;123: 257-69.

3. Nepal MK, Gurung CK, Jha AK, et al. First 150 patients of a new psychiatric OPD: Sociodemographic profile and their diagnostic status. J Nep Med Assoc $1986 ; 424: 7-19$

4. Shrestha NM. A prospective analysis of 300 cases attending outpatient clinic in Mental Hospital. In: Proceedings of the Workshop on National Mental Health Planning, Kathmandu, 1987;47-73.

5. Sharma BB. Socio-demographic analysis of 100 cases seen at Pokhara Mental Health Clinic. In: Proceedings of the Workshop on National Mental Health Planning, Kathmandu, 1987;74-82.

6. Upadhyaya KD, Pol K. A mental health prevalence survey in two developing towns of western region. J Nep Med Assoc 2003;42:328-30.

7. Regmi KR, Khalid A, Nepal MK, et al. A study of sociodemographic characteristics and diagnostic profile in psychiatric outpatients of TUTH. Nepalese Journal of Psychiatry 1999;1:26-33.

8. Wright C. Community mental health services in Nepal- early experiences. In: Proceedings of the Workshop on National Mental Health Planning, Kathmandu, 1987;13-27.

9. Upadhayay KD, Dutta S, Singh G. Morbidity profile of patients attending neuropsychiatric OPD at the western regional hospital, Pokhara. J Nep Med Assoc 1999;38:67-70.

10. Jha A, Adhikari SR. Mental Health Services in New Nepal Observations, Objections and Outlooks for the Future. J Nep Med Assoc 2009;48:185-90.

11. Shakya DR. Mental Health in New Nepal. In: Souvenir of the 24 All Nepal medical Conferences (ANEMECON);2009;62 -64.
12. Central Bureau of Statistics. National Population and Housing Census, 2012.

13. World Health Organization. The ICD-10 Classification of Mental and Behavioral disorders (Tenth Revision): Diagnostic Criteria for Research; Geneva: 1992.

14. Soren S, Bhutto ZA, Kumari P, et al. A socio-demographic study of patients attending DMHP, Dumka. Eastern J Psychiatry 2008;11:9-13.

15. Gaurie-Devi M, Rao VN, Prakashi R. Neuro-epidemiological study in semiurban and rural areas in South India: Patterns and International research. Oxford \& IBH Publishing Co. Pvt. Ltd., New Delhi;1985:11-21.

16. Dubey KC. A study of prevalence and biosocial variables in mental illness in a rural and urban community in Uttar Pradesh, India. Acta Psychiatr Scand 1970;46:327-59.

17. Sethi BB, Gupta SC, Kumar R, Kumar P. A psychiatric survey of 500 rural families. Indian J Psychiatry 1972; 14:183-96.

18. Vergeese A, Beig A, Sebseman LA, et al. A social and psychiatric study of a representative group of families in Vellore town. Indian J Med Res 1973;61:608-20.

19. Nandi DN, Ajmani S, Ganguly H, et al. Psychiatric disease in a rural community in West Bengal: an epidemiological study. Indian J Psychiatry 1975;17:87-99.

20. Waraich BK, Raj L, Chavan BS, et al. Decentralization of Mental Health Services under DMHP. Indian J Psychiatry 2003;45:161-65.

21. Wig NS, Murthy RS, Harding TW. A model for rural psychiatric services - Raipur rani experience. Indian J Psychiatry 1981;23:275-90.

22. Choo CH. Profile of patients seeking psychiatric treatment from the adult public mental health services in Singapore. Ann Acad Med Singapore 1997; 26:443-48.

23. Uys LR, Dlamini NK, Mabandla SP. A profile of selected psychiatric out patients in South Africa. Curationis 1995;18:22-5. 